Revue d'histoire de l'Amérique française

REYUE D.HISTOIRE DE L'AMÉRIQUE FRANÇAISE

PHILLIPS, Jim, Tina LOO et Susan LEWTHWAITE, Essays in the

History of Canadian Law, volume 5: Crime and Criminal Justice (Toronto, Osgoode Society, University of Toronto Press, 1994).

\title{
Brian Young
}

Volume 50, numéro 3, hiver 1997

URI : https://id.erudit.org/iderudit/305588ar

DOI : https://doi.org/10.7202/305588ar

Aller au sommaire du numéro

Éditeur(s)

Institut d'histoire de l'Amérique française

ISSN

0035-2357 (imprimé)

1492-1383 (numérique)

Découvrir la revue

Citer ce compte rendu

Young, B. (1997). Compte rendu de [PHILLIPS, Jim, Tina LOO et Susan LEWTHWAITE, Essays in the History of Canadian Law, volume 5: Crime and Criminal Justice (Toronto, Osgoode Society, University of Toronto Press, 1994).] Revue d'histoire de l'Amérique française, 50(3), 472-474.

https://doi.org/10.7202/305588ar d'utilisation que vous pouvez consulter en ligne.

https://apropos.erudit.org/fr/usagers/politique-dutilisation/ 
PHILLIPS, Jim, Tina LOO et Susan LEWTHWAITE, Essays in the History of Canadian Law, volume 5: Crime and Criminal Justice (Toronto, Osgoode Society, University of Toronto Press, 1994).

La publication de ce volume est une bonne occasion de rappeler aux lecteurs de la RHAF l'importance de The Osgoode Society for Canadian Legal History. Établie en 1979 dans le but de stimuler l'intérêt, la recherche et les publications en histoire du droit, la Osgoode Society regroupe des historiens professionnels et des praticiens du droit. Patronnée par le Barreau ontarien et plusieurs des plus grands bureaux d'avocats canadiens, la Osgoode Society subventionne les recherches d'étudiants aux cycles supérieurs et a mis sur pied un projet d'histoire orale. Celui-ci implique des entrevues avec plus de 200 avocats à travers l'Ontario, des juges de la Cour suprême du Canada et des cours provinciales d'Ontario, et des directeurs des services de police.

Depuis 1981, la société Osgoode a publié vingt-huit volumes en histoire du droit dont plusieurs traitent du Québec. Mentionnons en particulier celui de Constance Backhouse, Petticoats and Prejudice: Women and Law in Nineteenth-Century Canada (1991), de Murray Greenwood, Legacies of Fear: Law and Politics in Quebec in the Era of the French Revolution (1993) et, plus récemment, de Beverley Boissery, A Deep Sense of Wrong: the Treason, Trials, and Transportation to New South Wales of Lower Canadian Rebels After the 1838 Rebellion (1995). L'histoire des femmes, la mentalité des Anglo-Québécois, et, chez Boissery, le mélange de l'imaginaire et de l'histoire chez les patriotes déportés en Australie, voilà une bonne feuille de route intellectuelle pour une société savante dont la plupart des 721 membres sont des praticiens.

Crime and Criminal Justice, qui représente le cinquième volume de la série d'ouvrages sur l'histoire du droit canadien, comprend 15 articles repartis sous quatre thèmes: les autochtones et le droit criminel; les femmes, le crime et la justice criminelle; les institutions de justice criminelle et l'autorité de l'État; les prisons canadiennes au XIX $\mathrm{X}^{\mathrm{e}}$ siècle.

Les auteurs qui traitent spécifiquement du Québec - John Dickinson, André Lachance, Sylvie Savoie et Jean-Marie Fecteau - abordent une question similaire pour la période prénapoléonienne; tous soulignent en effet le rôle de la communauté - et non pas de l'État - comme véhicule de contrôle sous l'Ancien régime. Citons Fecteau: «l'État 'absolutiste' était fondamentalement un état 'minimaliste'.» (p. 296)

Suivant l'argument de W. J. Eccles, John Dickinson insiste sur le fait que les communautés autochtones, tels les Iroquois et les Abenakis, bénéficiaient - même au cœur de la colonie de la Nouvelle-France - d'une sorte de souveraineté-association qui leur permettaient d'être largement indépendants de l'autorité française. Dans leur étude de la famille, intitulée Violence et honneur familial dans la Nouvelle-France, Lachance et Savoie montrent bien que les classes populaires n'aimaient pas assister à des procès ou à des punitions publiques et préféraient régler un comportement répréhensible ou 
une question d'honneur par la surveillance et d'autres formes de contrôle exercé par la communauté. Toujours avec une approche plus théorique que la plupart des autres historiens du droit canadien, Fecteau, dans son étude sur la pauvreté, la criminalité, et le pouvoir étatique, montre que le régime de coercition, de répression et de réformes institutionnelles qui caractérise le $\mathrm{XIX}^{\mathrm{e}}$ siècle faisait partie intégrante d'un système plus large de contrôle social.

On trouve beaucoup moins d'unanimité et de cohérence chez les historiens qui traitent des institutions judiciaires hors Québec. Dans le reste du Canada, on préfère l'étude régionale ou métropolitaine, l'étude de cas, ou l'histoire narrative. Le résultat est frappant: le reste du Canada est présenté sans une vue d'ensemble claire alors que le Québec semble beaucoup plus uni et homogène qu'en réalité. Constance Backhouse et Carolyn Strange, par exemple, s'intéressent à l'évolution du patriarcat. En cette fin de siècle, on peut facilement oublier que l'avortement était considéré comme un acte criminel pendant la première moitié du $\mathrm{XX}^{\mathrm{e}}$ siècle. Utilisant la méthode de l'étude de cas, Backhouse présente deux espèces d'avorteurs: le médecin mâle et l'avorteur non professionnel, homme ou femme. Elle en arrive à la conclusion que $74 \%$ des individus accusés d'être des avorteurs étaient des hommes, dont beaucoup de médecins (p. 255). Dans le cas des femmes, plusieurs étaient sages-femmes.

Pour sa part, Strange voit les procès pour viol dans le comté de York entre 1880 et 1930 «as much urban morality tales as trials of men charged with rape». Selon l'auteure, les autorités torontoises et les jurys étaient davantage préoccupés par les problèmes sociaux d'ivresse, de jeu, et de prostitution que par la violence sexuelle. Les immigrants, les non-chrétiens et les Noirs étaient visés plus que les mâles de bonnes familles. Le système de justice criminelle, insiste-t-elle, fait partie d'un processus qui incite les femmes à ne pas percevoir un assaut sexuel comme un crime (p. 240).

Ces études qui mettent en évidence le caractère patriarcal de la société tranchent avec l'image que Peter Oliver donne du Mercer Reformatory, une prison pour femmes établie à Toronto en 1879. Oliver considère cette prison comme une institution «remarquable» (p. 366) parce qu'elle était gérée par des femmes impliquées dans le mouvement féministe, ce qui s'est traduit par une culture carcérale différente à bien des égards des prisons pour hommes. Alors que la répression régissait ces dernières, dans cette prison pour femmes dominait la volonté de réformer les prisonnières, tout en leur inculquant le respect de soi et la sobriété. Oliver oublie toutefois de considérer que ces administratrices femmes étaient complices d'un monde carcéral et judiciaire basé sur des valeurs masculines et qu'elles acceptaient le statu quo en ce qui concerne les relations entre les sexes.

Pour ceux qui s'intéressent aux formes de la justice dans les colonies britanniques, les travaux de Hamar Foster de l'université de Victoria sont toujours d'un grand intérêt. Dans ce volume, il traite de la question du meurtre entre Amérindiens et Europi ens en Colombie britannique. Avant 1850, les 
rapports légaux entre marchands et autochtones étaient réglementés par les droits américain, britannique, et parfois amérindien. L'établissement de la colonie et la découverte d'or en 1858 ont changé les rapports de force. En 1853, deux autochtones - dont l'un était le fils d'un chef de Nanaimo - ont été jugés et pendus à la suite d'un procès pour meurtre par la justice criminelle anglaise. La conclusion est claire: «Colonization always involves two parties of unequal power and sophistication... and Aboriginal peoples laboured under significant disadvantages in a common law trial.» (p. 82) Sur 26 hommes pendus pour meurtre avant 1871 dans les colonies de Vancouver Island et la Colombie britannique, 23 étaient autochtones.

Bien que le Québec et le reste de Canada aient deux systèmes de droits civils fondamentalement différents, ils partagent bien entendu leur système de justice criminelle. Les articles portant sur la prison de Saint-John, le travail des condamnés à Toronto, les homicides en Colombie Britannique et les femmes et le crime à Halifax, que l'on retrouve également dans cet ouvrage, sont donc tous d'une grande pertinence historique pour les lecteurs québécois.

Dans cette période postréférendaire, où l'on a un sens très fort de «soi» mais très peu le sens de la culture de «l'autre», ce livre peut être utile, car il constitue une bonne introduction à la diversité et à la richesse des recherches sur la justice criminelle à travers le Canada. Et si on a du mal à dégager une vue d'ensemble de la justice criminelle au Canada, c'est que, comme le rappellent les rédacteurs qui insistent sur les multiples ambiguiités de la culture légale du Canada, «the assertion of authority through the criminal law mirrored the ambiguities inherent in state formation» (p. 12). 